\title{
Isolated bilateral fetal pleural effusion: diagnosed on antenatal ultrasonography
}

\author{
Ansari $S,{ }^{1 *}$ Ahmad $K,{ }^{1}$ Dhungel $K,{ }^{1}$ Gupta $M K,{ }^{1}$ Rauniyar $R K,{ }^{1}$ Kumar $A^{1}$ \\ ${ }^{1}$ Department of Radiodiagnosis and Imaging, B.P. Koirala Institute of Health Sciences, Dharan, Nepal.
}

\author{
*Corresponding Author: \\ Dr. Sajid Ansari, MD, \\ Department of Radiodiagnosis and imaging, \\ B.P. Koirala Institute of Health Sciences, Dharan, Nepal. \\ Address: H-2733, BPKIHS, Dharan, Nepal. \\ Mobile no.: 00977-9722541028 \\ Email address: drsajidansari@yahoo.co.in
}

\section{Citation}

Ansari S, Ahmad K, Dhungel K, Gupta MK, Rauniyar RK, Kumar A. Isolated bilateral fetal pleural effusion: diagnosed on antenatal ultrasonography. Nepal Journal of Medical Sciences 2014;3(1):76-8.

\begin{abstract}
Isolated fetal pleural effusion is a rare condition with high mortality. When there are no other findings of hydropsfetalis or documented etiology such as inflammatory, iatrogenic or cardiac problems exist, isolated pleural effusion is considered. We present a rare case of isolated bilateral fetal pleural effusion diagnosed prenatally on ultrasonography.
\end{abstract}

Keywords:Antenatal ultrasonography; fetus;pleural effusion

\section{Introduction:}

Isolated fetal pleural effusion is a rare condition which results from an accumulation of fluid in the space between parietal and visceral pleura. ${ }^{1}$ It occurs at frequency of nearly 1 in 15,000 pregnancies. $^{2}$ Prenatally it can be detected on ultrasonography (USG) which appears an anechoic peripheral space in the thorax compressing the lung fields. Small pleural effusions are seen as thin echolucent rim surrounding the lung tissue and may also outline mediastinal structures. In most of the cases it is bilateral; however unilateral fetal pleural effusion has also been reported. ${ }^{3,4}$ Large bilateral pleural effusions produce a characteristic 'bat-wing appearance' with the lungs appearing free-floating alongside the heart. Large effusions cause mediastinal shift and eversion of the diaphragm.

\section{Case report:}

A 27 years old primigravida at 23 weeks of gestation was referred for ultrasonography (USG) for assessment of fetal wellbeing. Her blood pressure and previous investigations including USG were normal. Present USG (Figures 1, 2 and 3) revealed large fetal pleural effusion on right side causing collapse of right lung with mediastinal shift towards contralateral side. Right hemidiaphragm was everted due to large pleural effusion. Mild left sided fetal pleural effusion was also noted.

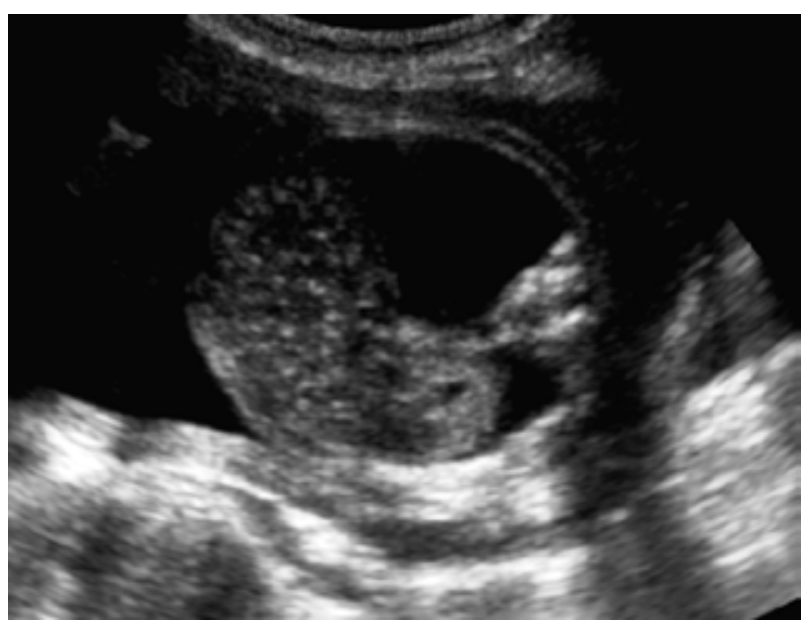

Figure 1: Transverse section through the fetal thorax showing large right sided pleural effusion and mild left sided pleural effusion. 


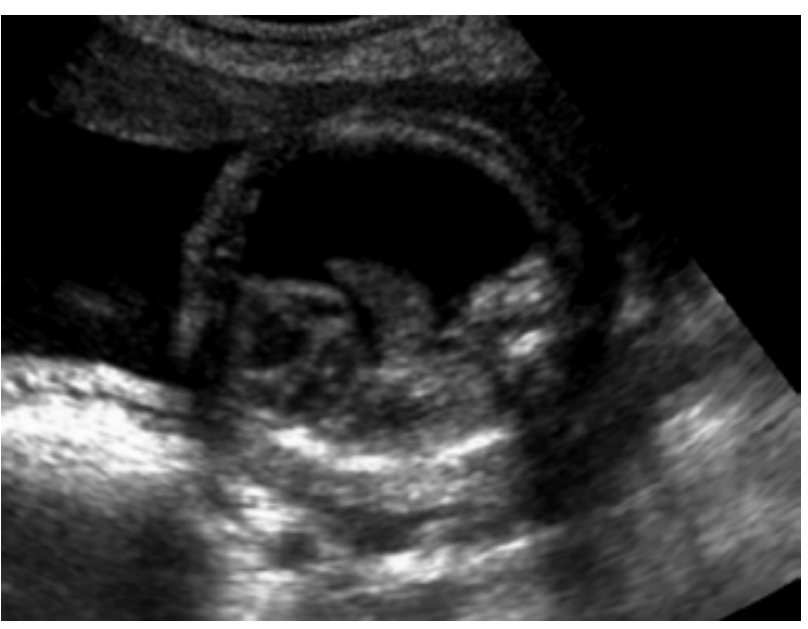

Figure 2: Transverse section through the fetal thorax showing large right sided pleural effusion with collapsed right lung and mild left sided pleural effusion.

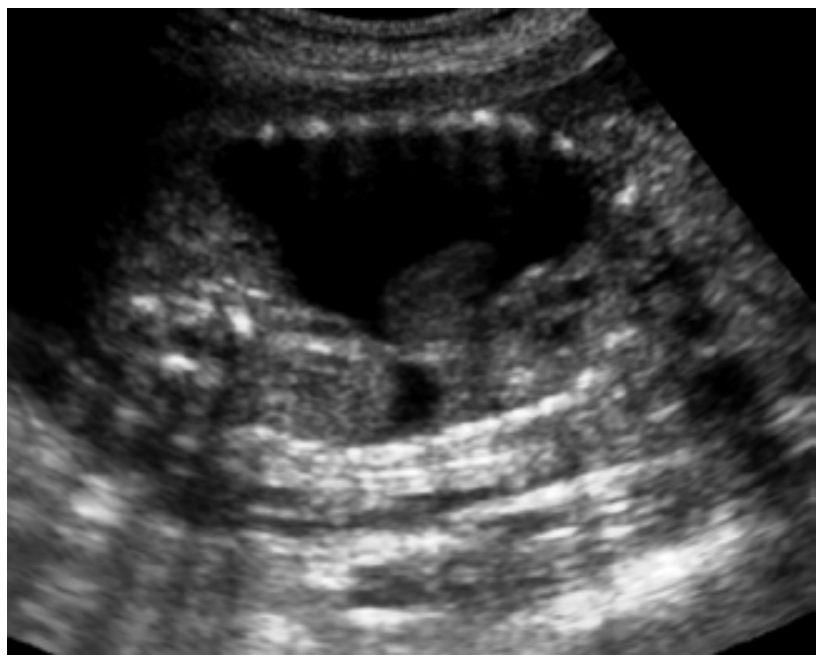

Figure 3: Coronal section through the fetal thorax showing large right sided pleural effusion causing collapse of right lung and eversion of right hemidiaphragm along with mild left sided pleural effusion.

There was no polyhydramnios, fetal ascites or pericardial effusion. Normal four chamber heart was seen displaced towards left side. Liquor volume was normal and placenta was normal in location. No obvious cardiac abnormality seen. Rest of the fetal organs was normal. Fetal echocardiogram showed no structural or functional abnormality. She tested negative for TORCH (toxoplasmosis, other infection, rubella, cytomegalovirus and herpes simplex), HIV (human immunodeficiency virus), HBsAg (hepatitis B surface antigen) and tuberculosis. Her hemoglobin level was normal.

Since pleural effusion was large and compromising the right lung, repeat USG was done after 2 weeks to look for any regression or progression in amount of fluid. There was progressive increment in the amount of fluid on serial USG scan. So looking after serial USG findings and further fetal/ maternal risks, parental counseling was done for in-utero therapy, but they refused for any interventional procedures.

\section{Discussion:}

Fetal hydrothorax or pleural effusion may be an isolated finding or associated with multiple fetal anomalies, congenital infection or isoimmunization. The condition may be primary or secondary. Fetal pleural effusion is most commonly seen in second or early third trimester and twice often in male fetuses. ${ }^{3}$ It has been associated with congenital malformations like bronchopulmonary sequestrations; congenital cystic adenomatoid malformations and congenital malformations of the lymphatics; Downs' syndrome and Turner's syndrome; congestive heart failure; cardiac defects; pulmonary lymphangiectasia; polydactyly; cystic hygroma; thoracic duct trauma and surgical interventions. ${ }^{5-7}$ Congenital infections associated with fetal pleural effusions are parvovirus B19, adenovirus and herpes simplex type I. It may occur as part of the overall manifestations of fetal hydrops which is associated with significant fetal mortality. When there is no documented etiology or fetal hydrops, it is designated as isolated pleural effusion. ${ }^{2,8}$

It has variable natural history depending upon the underlying pathology with varying degree of outcome i.e. the effusion may regress spontaneously; remain stable in size or progress to involve both sides of the chest and produce fetal hydrops, pulmonary hypoplasia and fetal/neonatal demise. ${ }^{2,5}$ The cases presenting in second trimester with unilateral pleural effusion and no fetal hydrops are most likely to regress spontaneously. USG along with fetal echocardiography and antenatal karyotyping will often reveal the underlying etiology. It can be easily diagnosed on prenatal USG.

Moderate and large effusions may produce mass effect resulting in mediastinal shift towards contralateral side and compromising development of the lung (pulmonary hypoplasia). Large bilateral pleural effusions can result in significant heamodynamic changes in the fetal circulation and progession to non-immune hydrops. Fetal hydrothorax leading to hydrops is often associated with mortality as high as $50 \% .^{2}$ In-utero therapy can be helpful to improve the prognosis by allowing lung expansion thereby preventing progressive hydrops and pulmonary hypoplasia. ${ }^{4}$ Isolated large pleural effusions present with severe respiratory distress at birth and usually have poor outcome.

In well tolerated unilateral pleural effusion, conservative approach should be taken followed by repeat USG after 2-3 weeks. If fluid regresses, then follow-up with regular USG should be done and if fluid is not regressing, in-utero pleuroamniotic shunt or thoracocentesis can be done. USG 
guided in-utero thoracocentesis frequently used but it carries risk for both mother and fetus; and also withdrawal of large amount of fluid may induce significant fetal distress. ${ }^{9}$ Shunting can be particularly useful if the fetus is younger than 32 weeks of gestation, prior to lung maturity and successful drainage may be achieved. ${ }^{10}$ Shunt complication includes migration, blockage and fetal death; and failure rates of up to $26 \%$ have been reported. ${ }^{10}$

\section{Conclusion:}

Thus, due to increased use of ultrasonography for antenatal screening, fetal pleural effusion can be easily diagnosed. Early recognition and prompt management of this condition can aid in better prognosis. Serial ultrasonography can be helpful for assessment of regression, stability or progression of effusions.

\section{References:}

1. Rocha G, Fernandes P, Rocha P, et al. Pleural effusions in the neonate. ActaPaediatr 2006; 95:791-8. http://dx.doi.org/10.1111/j.1651-2227.2006.tb02342.x

2. Longaker MT, Laberge JM, Dansereau J, et al. Primary fetal hydrothorax: natural history and management. J PediatrSurg 1989; 24:573-6.

http://dx.doi.org/10.1016/S0022-3468(89)80509-3

3. Rustico MA, Lanna M, Coviello D, et al. Fetal pleural effusion. PrenatDiagn2007;27:793-9.

http://dx.doi.org/10.1002/pd.1768

4. Yinon Y, Kelly E, Ryan G.F, etal. pleural effusions. Best Pract Res ClinObstetGynaecol2008; 22:77-96.

http://dx.doi.org/10.1016/j.bpobgyn.2007.09.004

5. Aubard Y, Derouineau I, Aubard V, et al. Primary fetal hydrothorax: A literature review and proposed antenatal clinical strategy. Fetal DiagnTher 1998;13:325-33.

\section{http://dx.doi.org/10.1159/000020863}

6. Hegay Z, Reece A, Roberts A, et al. Isolated fetal pleural effusion: a prenatal management dilemma. ObstetGynecol 1993;81:147-52.

7. Schluter G, Steckel M, Schiffmann H, G et al. Prenatal DNA diagnosis of Noonan syndrome in a fetus with massive hygromacolli, pleural effusion and ascites.
PrenatDiagn 2005;25:574-6.

http://dx.doi.org/10.1002/pd.1189

8. Grover SB, Gupta P, Chellani H, et al. Spontaneous neonatal pleural effusion. Indian J Radiol Imaging $2007 ; 17: 71-3$.

http://dx.doi.org/10.4103/0971-3026.33612

9. Jeanty C, Nien JK, Espinoza J, et al. Pleural and pericardial effusion: a potential ultrasonographic marker for the prenatal differential diagnosis between congenital diaphragmatic eventration and congenital diaphragmatic hernia. Ultrasound ObstetGynecol 2007;29:378-87.

http://dx.doi.org/10.1002/uog.3958

10. Tsao KJ, Albanese CT, Harrison MR. Prenatal therapy for thoracic and mediastinal lesions. World J Surg 2003;27:77-83.

http://dx.doi.org/10.1007/s00268-002-6740-7 